\title{
Productivity dynamics of oak forests of the Crimean Peninsula
}

\author{
Roman Gorbunov* \\ IBSS, 299011 Sevastopol, Russia
}

\begin{abstract}
The work proposes a methodology for studying the productivity dynamics of forest ecosystems based on remote sensing data. The possibility of using the NDVI vegetation index to study the interannual variability in productivity of regional ecosystems is shown. The long-term productivity dynamics of oak forests of the Crimean Peninsula is analyzed. On the basis of the data series obtained, the periods characterized by peculiarities of the productivity dynamics of forest ecosystems are identified.
\end{abstract}

\section{Introduction}

The history of GIS-modeling of ecosystem functioning and dynamics is extremely extensive. NDVI (Normalized Difference Vegetation Index) is often used as an indicator of ecosystem productivity, which is one of the many indexes developed at present to determine the biological ecosystems productivity based on the calculation of multispectral space images channels ratio [1-6]. NDVI index among the whole variety of vegetation indexes is one of the basic ones and has a great practice in determination, well-established methodology of interpretation data obtained and is already built as automatic scripts into modern geoinformation software packages.

Consideration of the index methodology within this work is not interesting, since it is formed and tested. It should only be noted that in criticizing the practice of using this index the question is raised concerning the necessity of comparing data with test sites to determine the actual biomass value, since the index is relative. In this study we are more interested in the productivity dynamics in relative values when climatic parameters change rather than actual biomass. It should also be noted that for the territory of Crimea, including natural plant communities, there is wide field experience in determining the communities' productivity, and the index interpretation is also possible, but in our studies is not necessary.

Many works are devoted to the productivity studying of forest ecosystems in Crimea. The most systematized data on the dynamics of forest communities and forests' productivity on the Crimean Peninsula are presented in the works of Yu.V. Plugatar [7-10]. At the same time, the presented works are focused on studying the productivity of specific trees' species, rather than ecosystems as a whole. In this regard, the aim of this work is to

\footnotetext{
*Corresponding author: karadag_station@mail.ru
} 
develop approaches and assess the interannual dynamics of the oak forests productivity on the Crimean Peninsula using remote sensing data.

\section{Materials and methods}

Landsat space images for the period from 1979 to 2017 were used as the research material. The images were obtained by downloading from the USGS open source (https://www.usgs.gov/). Images with the maximum set of color channels of Level 1 GeoTIFF Data Product type were selected from the entire satellite data catalogue. A total of 277 space images were received for different periods with different territorial coverage of the Crimea. The sensor resolution of each image is $30 \times 30 \mathrm{~m}$. Specifics of Landsat satellite orbit and camera operation peculiarities divide the territory of the Crimea into 4 overlapping segments, which, when overlaid, allow getting quite a detailed display of the territory in multichannel spectrum. The images were processed in ArcGis 10.4.2 program.

Features and history of the Landsat project do not provide an opportunity to get a complete set of all four satellite image segments for each of the interesting periods. In some cases 2, 3 or even 1 image segment may be presented for one date, depending on the image orbit passage. In addition, there is a certain shift of some images when switching from satellite to satellite (the period from 1979 to 2017 covers the operation of Landsat3, Landsat4, Landsat5, Landsat7 and Landsat8 satellites).

In addition, the presence of clouds in the images is very important when selecting images. The cloud minimization rule in the image was used.

It is important to select the date range, within which the image segments can be identical to the connection. Taking into account that the main purpose of image analysis is to estimate the dynamics of biological productivity, the target period for our studies is the vegetation period.

Besides, analysis of the images presented in the project allows concluding that in winter and even in autumn and spring almost all space images have cloud cover. In some cases it reaches $100 \%$ and does not allow using the image.

Within the vegetation period, we chose August as the month. In the period of this month for the period from 1979 to 2017 the images are available on the following dates: 01.08 , $05.08,06.08,12.08,16.06,20.08,26.08,29.08,31.08$. The whole range of images was processed, images with cloudiness was rejected.

The choice of sequences overlay images is conditioned by the rule as the cloudiness is removed and the date approaches the middle of the vegetation period and the middle of August.

The space images database analysis shows that it is not appropriate to use the June month images, as in this case the maximum value of biological diversity for this period has not been reached. In July the biomass value is considerably higher, however in practice almost every space image contains cloud cover, especially within the Mountainous Crimea, which is associated with high precipitation value in this period in Crimea. Taking this into account it is rather difficult and not appropriate to use July images.

Thus, both from a technical and logical point of view, the using of images for August month is the most optimal, because on the one hand, during this period a higher biomass value has been achieved, and on the other hand, images for this period are "the cleanest" from the clouds, and for almost every year of the selected period it is possible to collect at least one "strip" of image over the territory of the Crimea.

To determine the NDVI index, the ArcGIS 10.4.2 image analysis module is used. Automatic calculation of the index value in this module is classified on a scale from 0 to 200 units (this range is designed for an 8-bit structure and can be displayed using a color scale or color grade, which makes its use more convenient), which can later be converted to 
the value of the index values in the range from 0 to 1 in the classical version of the index interpretation. Given that the task of our work is to compare the value of biological productivity, rather than interpretation the vegetation cover, the use of standard ArcGis 10.4.2 scale is more convenient for work.

A database of ecosystem productivity values has been compiled in order to analyse the multiannual spatio-temporal dynamics of ecosystem productivity as a reflection of changes in multi-year ecosystem states. The landscape and typological map of the Crimean Peninsula compiled by G.E. Grishankov [11] was used as an operational and territorial unit of the analysis.

\section{Results}

As a result of the research, a database on the productivity value of Crimean ecosystems was compiled based on multispectral space images' data for the period 1979-2017.

The results of productivity studies of forest ecosystems in Crimea, obtained on the basis of their multiannual field study, are presented in the works of Yu. V. Plugatar. These results were compared with data obtained from remote sensing over a multiannual period.

In the most general form, all oak forests on the Crimean peninsula should be divided into two large predominant subgroups - forests of Quercus petraea and forests of Quercus pubescens.

\subsection{Quercus petraea forests}

$\mathrm{Yu}$.V. Plugatar, considering the value of productivity of this forests group notes [9] the exactingness of this species to soil humidity, as well as the fact that Quercus petraea tree stands are not sufficiently productive and are characterized by a spatial prevalence of forests with low bonitet. It is noted that among the tree stands the most productive are forests in fresh sudubrava with an average stockpile of $153 \mathrm{~m}^{3} / \mathrm{ha}$.

Within the landscape differentiation, Quercus petraea forests are represented within contours № 60-71 in the mid-mountain landscape belt and contours № 48-55 in the lowmountain landscape belt [11]. As an example of multiannual dynamics of changes in ecosystem states, expressed in the form of the "effect" of productivity, let's choose contour No. 68 (mid-mountain slope, dissected beams with oak and mixed broad-leaved forests). These contours by landscape and ecotopic conditions most fully correspond to fresh sudubrava.

In this case it is necessary to make a certain correction - Yu.V. Plugatar conducts an analysis of forest productivity in this case and subsequent variants for multiannual timber stockpile with corresponding calculations of its stockpiles. In our case, with the help of the NDVI index it is clearly possible to fix and consider in the multiannual dynamics the amount of biomass contained in the plant leaf apparatus, which as a result, in the multiannual section provides growth and accumulation of biomass in wood.

Fig. 1 shows the values of forest productivity changes in this contour as of August month.

The average value of the NDVI index is in the range of 140-150 units, while the established multiannual norm is possible to consider the value of 146-148 units, which on average may correspond to the value of actual productivity of $153 \mathrm{~m}^{3} /$ ha, determined on the basis of multiannual observations of $\mathrm{Yu} \mathrm{V}$. Plugatar [9]. The minimum values for this landscape contour are in the range of 70-120 units, and the maximum values are in the range of 165-170 units, which indicates a decrease in actual productivity to $70 \mathrm{~m}^{3} / \mathrm{ha}$ in certain landscape parts and its possible increase to $165-170 \mathrm{~m}^{3} /$ ha in some areas depending on changes in ecotopic conditions. 


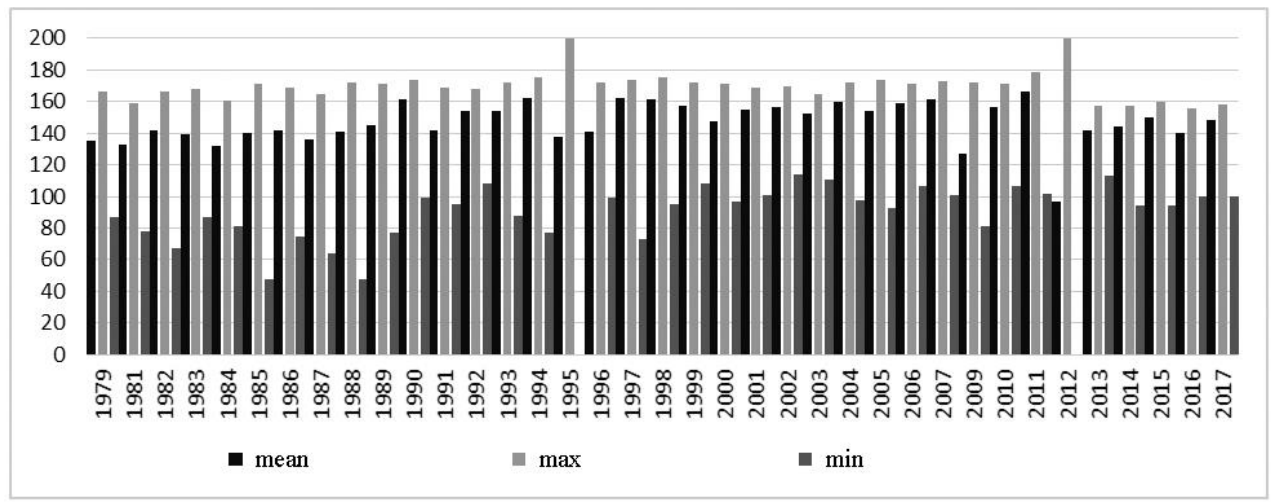

Fig. 1. Multiannual changes in productivity values for mid-mountain slope, dissected beams with oak and mixed broad-leaved forests landscape.

Thus, for landscape types of the Crimean territory, it is possible to identify types of ecosystem conditions depending on the of productivity value at the level of normal productivity, decreased productivity and increased productivity.

Consideration of the multiannual indicator dynamics reveals certain periods in the form of peculiar waves. The period from 1979 to 1988 is characterized by a normal level of productivity ecosystems under consideration with insignificant parameter fluctuations; the period from 1989 to 1998 tends to increase parameter fluctuations and the appearance of single states of reduced and increased productivity. Further the period from 1999 to 2007 is characterized by sustainable parameter values in the range close to the increased productivity, and in the period from 2008 to present days there is a sharp fluctuation of parameters towards chaotic changes in the increased and decreased direction, which can testify to certain tendencies of parameters' change of heat and moisture supply towards fluctuation of temperature norms and values of precipitation.

\subsection{Quercus pubescens forests}

Within the landscape differentiation of the Crimean Peninsula Quercus pubescens forests are represented within the contours № 92-98 in the mid-mountain landscape belt and contours № 48-55 in the low-mountain landscape belt [11]. As an example of the multiannual dynamics of changes in ecosystem states, expressed as an "effect" of productivity, we choose contour № 95 (mid-mountain stepped-slope with oak and mixed broad-leaved forests).

Yu.V. Plugatar notes [9] that these forests are represented in 8 types of ecotopes with spatial predominance of one of them - dry sudubrava, and the average actual productivity is $83-110 \mathrm{~m}^{3} /$ ha depending on age.

By its habitat conditions landscape contour № 95 is close to the ecotope of dry sudubrava. Fig. 2 shows the multiannual dynamics of the NDVI index for this ecosystems type in Crimea.

Consideration of the presented diagram shows more significant average values' fluctuations of the considered value in the given ecosystems type at the level of 120-150 units, with average normal values in the range of 135-138 units. The maximum values are more sustainable in time and fluctuate in the range of 150-160 units with local maximums up to 200 units. The minimum index values for Quercus pubescens forests are lower than those for Quercus petraea forests and range from 30 to 90 units, with a minimum normal value of about 50-55 units. 


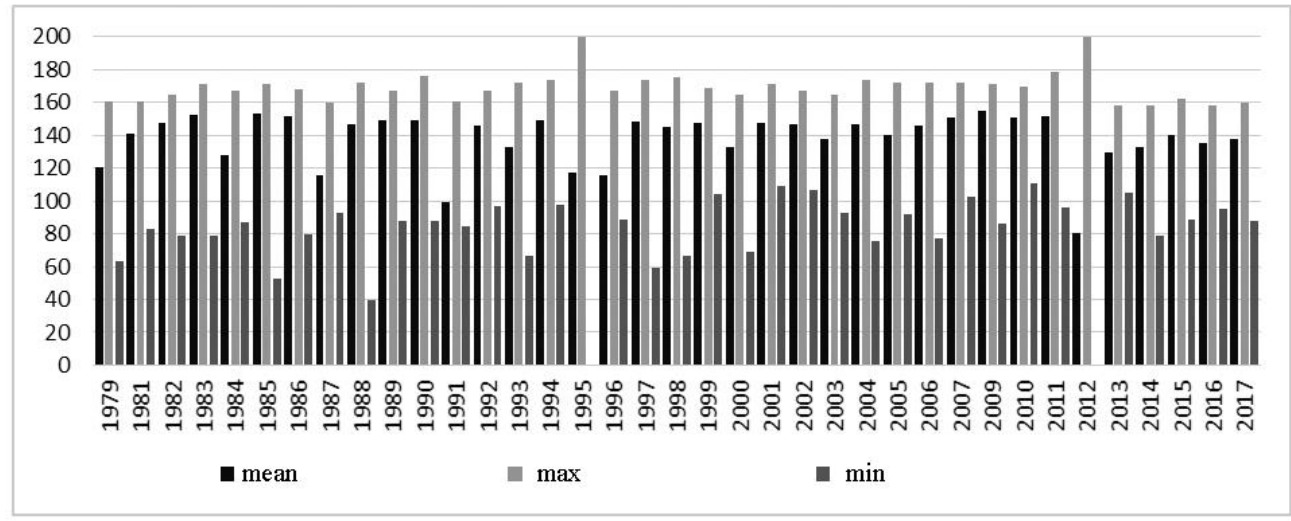

Fig. 2. Multiannual changes in productivity values for mid-mountain steppe-slope landscape ecosystems with oak and mixed broad-leaved forests.

Empirical generalization allows to conclude that depending on ecotopic conditions the actual productivity value at normal range of states is within $90-95 \mathrm{~m}^{3} / \mathrm{ha}$, minimum $85-90$ $\mathrm{m}^{3} / \mathrm{ha}$, maximum $95-100 \mathrm{~m}^{3} / \mathrm{ha}$, with the necessary correction for the age of planting.

Consideration of the temporal dynamics of this parameter for Quercus pubescens forests shows great differences in comparison with Quercus petraea forests, which confirms a more significant productivity dependence not only on moisture conditions, but also on temperature states.

From 1979 to 1986 , there was a gradual increase in the productivity value with a local decline in 1984 (this year is distinguished by excellent circulation conditions and local minimum precipitation) from normal values to higher values.

The period from 1987 to 1996 is characterized by significant fluctuations in productivity, which as a result, in interrelation with hydrothermal conditions leads to the formation of an unstable picture of the ecosystems state in productivity value with the presence of sharp skips from year to year.

The period from 1997 to 2010 is characterized by sustainable increased productivity values in the range of 138-152 units of the index, with minor decreases in 2000, 2002, 2005.

The period from 2010 to present is characterized by some decline in productivity of Quercus pubescens forests after a sharp local decline in 2012 (obviously unfavorable dry conditions prevailed in this year during almost all seasonal ecosystem states) and the approaching of productivity to the normal ecosystems state.

\section{Conclusion}

Thus, on the basis of remote sensing data the series of data on productivity values spatial dynamics of oak forests growing on the territory of the Crimean peninsula were obtained, the periods characterizing the main regularities of temporal productivity values variability of the considered forest ecosystems were revealed.

The results obtained will allow to reveal further connection between spatio-temporal dynamics of oak formations productivity and regional climate change manifestations. The proposed research methodology is universal for any type of regional ecosystems.

The study was made as part of the IBSS research (registration number: AAAA-A19-119061-190081-9). 


\section{References}

1. N. Pettorellia, J. Vik, A. Mysteruda, J.-M. Gaillardb, C.J. Tuckerc, N.C. Stensetha, Trends in Ecology and Evolution, 20, 503-510 (2005)

2. G. Hmiminaa, E. Dufrênea, J.Y. Pontaillera et al., Remote Sensing of Environment, 132, 145-158 (2013)

3. G. MeeraGandhia, S. Parthibanb, Nagaraj Thummalu, A. Christyd, Procedia Computer Science, 57, 1199-120 (2015)

4. D.P. Roya, V. Kovalskyya, H.K. Zhanga, E.F. Vermoteb, L. Yana, S.S. Kumara, A. Egorova, Remote Sensing of Environment, 185 (2016)

5. N. Mishraa, D. Heldera, J. Barsib, B. Markhamc, Remote Sensing of Environment, 185 (2016)

6. G.V. Lobanov, A.I. Bashkirskii, A.Yu. Zvereva, B.V. Trishkin, A.P. Protasova, Scientific notes of the Bryansk State University, 2, 57-61(2016) (in Russian)

7. Yu.V. Plugatar, From Crimean forests (Novoe Slovo, Kharkiv, 2008) (in Ukrainian)

8. A.F. Polyakov, Yu.V. Plugatar, Forest formations of Crimea and it ecological role (Novoe Slovo, Kharkiv, 2009) (in Russian)

9. Yu.V. Plugatar, Forests of Crimea (IT ARIAL, Simferopol, 2015) (in Russian)

10. Yu.V. Plugatar, S.P. Korsakova, O.A. Ilnitsky, Ecological monitoring of Soutern coast of Crimea (IT ARIAL, Simferopol, 2015) (in Russian)

11. E.A. Pozachenyuk (Ed.), Modern landscapes of the Crimea and adjacent water areas (Business-Inform, Simferopol, 2009) (in Russian) 